\title{
Sound variation and function in captive Commerson's dolphins (Cephalorhynchus commersonii)
}

\section{$\operatorname{AUTHOR}(\mathrm{S})$ :}

Yoshida, Yayoi M.; Morisaka, Tadamichi; Sakai, Mai; Iwasaki, Mari; Wakabayashi, Ikuo; Seko, Atsushi; Kasamatsu, Masahiko; Akamatsu, Tomonari; Kohshima, Shiro

\section{CITATION:}

Yoshida, Yayoi M.... [et al]. Sound variation and function in captive Commerson's dolphins (Cephalorhynchus commersonii). Behavioural Processes 2014, 108: 11-19

\section{ISSUE DATE:}

2014-10

URL:

http://hdl.handle.net/2433/191115

\section{RIGHT:}

C 2014 Elsevier B.V.; この論文は出版社版でありません。引用の際には 出版社版をご確認ご利用ください。; This is not the published version. Please cite only the published version. 
1 Title

2 Sound variation and function in captive Commerson's dolphins

3 (Cephalorhyncus commersonii)

4

5 Authors

6 Yayoi M. Yoshida1, Tadamichi Morisaka1,2, Mai Sakai2, 3, Mari Iwasaki",

7 Ikuo Wakabayashi ${ }^{5}$, Atsushi Seko $^{5}$, Masahiko Kasamatsu ${ }^{5}$, Tomonari

8 Akamatsu $^{6,7}$, Shiro Kohshima ${ }^{1}$

9

10 (1) Wildlife Research Center, Kyoto University, Tanaka-sekiden, Sakyo-ku, 11 Kyoto, 606-8203, Japan

12 (2) Institute of Innovative Science and Technology, Tokai University, 3-20-1,

13 Orido, Shimizu-ku, Shizuoka 424-8610, Japan

14 (3) JSPS, 5-3-1 Kojimachi, Chiyoda-ku, Tokyo 102-0083, Japan

15 (4) Tokyo Institute of Technology, W3-43 2-12-1, Ookayama, Meguro-ku, 16 Tokyo 152-8551, Japan

17 (5) Toba Aquarium, 3-3-6, Toba-city, Mie, 517-8517, Japan

18 (6) National Research Institute of Fisheries Engineering, Hasaki, Ibaraki, 19 314-0408, Japan

20 (7) CREST, Japan Science and Technology Agency, Gobancho, Chiyoda-ku, 21 Tokyo, 102-0075, Japan 


\section{Abstract}

25 Commerson's dolphin (Cephalorhyncus commersonii), one of the smallest 26 dolphin species, has been reported to produce only narrow-band 27 high-frequency (NBHF) clicks and no whistles. To clarify their sound 28 repertoire and examine the function of each type, we analysed the sounds 29 and behaviour of captive Commerson's dolphins in Toba Aquarium, Japan. 30 All recorded sounds were NBHF clicks with peak frequency $>110 \mathrm{kHz}$. The 31 recorded click-trains were categorised into four types based on the changing 32 pattern of their Inter-click intervals (ICI): Decreasing type, with 33 continuously decreasing ICI during the last part of the train; Increasing type, 34 with continuously increasing ICI during the last part; Fluctuating type, with

35 fluctuating ICI; and Burst-pulse type, with very short and constant ICI. The 36 frequency of the Decreasing type increased when approaching an object 37 newly introduced to the tank, suggesting that the sound is used for 38 echolocation on approach. The Burst-pulse type suddenly increased in front 39 of the object and was often oriented toward it, suggesting that it was used for 40 echolocation in close proximity to the object. In contrast, the Increasing type 41 was rarely recorded during approach, but increased when a dolphin 42 approached another dolphin. The Increasing and Burst-pulse types also 43 increased when dolphins began social behaviours. These results suggest that 44 some NBHF clicks have functions other than echolocation, such as 45 communication. 


\section{Introduction}

Commerson's dolphin (family Delphinidae, Cephalorhyncus commersonii) is the smallest dolphin inhabiting the inshore waters of Argentina, the Strait of Magellan, and the Falkland and Keruguelen Islands in the Indian Ocean.

2 Like other toothed whales (Odontoceti), Commerson's dolphins produce pulse 3 sounds for echolocation (Watkins and Schevill, 1980). However, the species 4 produces only pulse sounds, and no whistle sounds (Dziedzic and De 5 Buffrenil, 1989; Evans et al., 1988; Hatakeyama et al., 1988; Kamminga and 6 Wiersma, 1982, 1981; Shochi et al., 1982; Watkins and Schevill, 1980), while 57 most other delphinids also produce whistles. These species use pulses mainly 8 for echolocation and whistles mainly for intra-specific communication (e.g., 9 Tursiops truncatus (Janik and Slater, 1998), Lagenorhynchus obliquidens 60 (Caldwell and Caldwell, 1971), and Sousa chinensis (Van Parijs and 1 Corkeron, 2001)).

2 Dolphins in the genus Cephalorhynchus, including Commerson's dolphin, two of the genus Lagenorhynchus (hourglass dolphin (L. cruciger) 4 and Peale's dolphin (L. australis)), those of the family Phocoenidae, and the 5 pygmy sperm whale (family Kogiidae, Kogia breviceps), all produce short (ca. 6 130-400 $\mu \mathrm{sec}$ ) and narrow-banded (ca. 10-20 kHz) high-frequency (ca. 120$7130 \mathrm{kHz}$ ) ultrasonic clicks (NBHF clicks) but no whistle sounds (Au, 1993; 8 Au et al., 1999; Dawson, 1988; Kyhn et al., 2010; Madsen et al., 2005; 9 Tougaard and Kyhn, 2010). This may be to avoid predation by killer whales, 0 as the frequency of NBHF clicks exceeds their auditory range (Morisaka and 1 Connor, 2007; Morisaka, 2012).

2 Although there are no reports of acoustic communication in 3 Commerson's dolphin, acoustic communication using NBHF pulse sounds 4 has been suggested in other NBHF species. Dawson (1991) showed that 5 highly repetitive "click-trains", resulting in a "cry", were often recorded 6 during aggressive behaviour in Hector's dolphin ( $C$. hectori). These "cry" 7 sounds were recorded more often in large groups than in small, suggesting a 8 relationship with social interaction. $\mathrm{NBHF}$ pulse sounds similar to the cry 79 sound were reported for all Cephalorhynchus species, including 80 Commerson's dolphin (C. commerosonii, C. hectori, C. heavisidii, C. eutropia) 
81 (Watkins et al., 1977). Harbour porpoise (Phocoena phocoena), which has a

82 body size and shape similar to that of Cephalorhynchus dolphins, may also

83 use high-repetition NBHF pulse sounds for communication, as these sounds

84 are frequently recorded during social interactions (e.g. aggressive behaviour,

85 and when approaching other individuals) (Clausen et al., 2010; Nakamura et

86 al., 1998). However, more precise analysis of the relationship between the

87 sounds and behaviour is necessary to conclusively demonstrate that acoustic communication using NBHF pulse sounds occurs in these species.

There have been some previous studies on the sounds of

90 Commerson's dolphin in the wild (Dziedzic and De Buffrenil, 1989; Watkins and Schevill, 1980) and in captivity (Hatakeyama et al., 1988; Shochi et al., 1982). Audible sounds similar to the cry sounds of Hector's dolphin were also recorded in some studies (Dziedzic and De Buffrenil, 1989; Hatakeyama et al., 1988; Shochi et al., 1982; Watkins and Schevill, 1980). However, most of these were brief descriptions of the dolphins' behaviours and sounds obtained using a band-limited recording system that recorded only low frequencies < $100 \mathrm{kHz}$ (Dziedzic and De Buffrenil, 1989; Watkins and Schevill, 1980), which does not cover the main frequency of the sound in Commerson's dolphin. Furthermore, most analysed the waveform of a single pulse, though the sounds of Commerson's dolphins consist of click-trains containing from a few dozen to several thousand sequential clicks

102 (Kamminga and Wiersma, 1982). There has been no precise analysis of these 103 click-trains. To examine the possibility of acoustic communication in this species using NBHF clicks, it is necessary to analyse and categorise the click-trains and study the relationships between click-train type and dolphin 106 behaviour.

In this study, we analysed the sounds of captive Commerson's dolphins to categorise their click-trains based on changing inter-click interval (ICI) patterns. We also analysed the relationships between click-train type and dolphin behaviours to infer the function of each type of click-train. Finally, we discuss the possible use of clicks for acoustic communication in this species. 


\section{2. Materials and methods}

\section{2.1. Study site and subject animals}

118 Video and acoustic recordings of Commerson's dolphins were made at the

119 Toba Aquarium, Mie prefecture, Japan, on July 25 (three animals) and

120 December 27-28 (four animals), 2007. We studied two adult females (Laura:

12118 years old, Lala: 16 years old), one adult male (Kai: 10 years old, unrelated

122 to Laura or Lala) and one juvenile male (Peace: 1 year old, son of Laura). All

123 were born in Japanese aquariums: Laura and Lala were born at the

124 Matsushima Aquarium, Miyagi prefecture, Japan in 1989 and 1991, 125 respectively, and have lived in the Toba Aquarium since March 1996. Kai 126 and Peace were born at the Toba Aquarium in 1997 and 2006, respectively. 127 On July 25, 2007, three dolphins, excepting Kai, were housed in the main 128 pool (Fig. 1, $8.4 \times 6.8 \mathrm{~m}$ and $3.4 \mathrm{~m}$ in depth, $194.2 \mathrm{~m}^{3}$ of water, temperature 129 of $\left.14^{\circ} \mathrm{C}\right)$, and Kai was housed in the sub-pool $(4.9 \times 5.0 \mathrm{~m}$ and $1.5 \mathrm{~m}$ in depth, $13036.75 \mathrm{~m}^{3}$ of water, temperature of $14^{\circ} \mathrm{C}$ ). On December 27-28, 2007, all four 131 dolphins were housed in the main pool.

\subsection{Recording of behaviour and vocalisation}

134 To clarify the vocalisation repertoire and analyse the relationship between 135 sound types and behaviour, we carried out sound recording and video 136 recording of behaviour during the daytime (9:00-17:30) on July 25, 2007, in 137 nine 30-min recording sessions, each starting on the hour. We observed and 138 recorded dolphin behaviour from an underwater observation window $(8 \times 6$ $139 \mathrm{~m}$ ) in the main pool that enabled observation across almost the entire tank 140 (Fig. 1). Video recordings were made using a Sony (Tokyo, Japan) HDR-HC3 141 video camera. Sounds were recorded using a hydrophone (Reson, 142 TC4013, Denmark; sensitivity $-211 \mathrm{~dB}$ re $1 \mathrm{~V} / \mu \mathrm{Pa}$ between $1 \mathrm{~Hz}$ to $170 \mathrm{kHz} \pm$ $1433 \mathrm{~dB}$ ), an amplifier (Reson, EC6081, Denmark) with 10-kHz high-pass and $144250-\mathrm{kHz}$ low-pass filters and $50 \mathrm{~dB}$ gain, and one channel of a data recorder 145 (EZ7510, NF corporation, Yokohama, Japan) which consisted of an 146 analogue-to-digital converter (16-bit resolution, 500-kHz sampling rate, $2-\mathrm{V}$ 147 dynamic range) with data stored on a 40-GB hard disk drive (HDD). The 148 hydrophone was placed on a side wall of the main pool at 1-m depth (Fig. 2). 
To assess reactions to a newly introduced object, we recorded

150 behaviour and vocalisations on December 27 and 28, 2007, from the same 151 observation window and the pool-side floor of the main pool. The object 152 introduced was a handle with two sucker discs affixed to the pool wall, used 153 by aquarium staff for support while cleaning the pool. The object was 154 attached to the wall of the main pool close to the hydrophone $(10 \mathrm{~cm}$ above the hydrophone, Fig. 2). Video recordings were made using two video cameras (HDR-HC3, Sony, Tokyo, Japan, and DM-IXYDVM5, Canon, Tokyo, Japan). In three 30-min recording sessions, each starting 5 min after introduction of the object, vocalisations were recorded with the same system and settings used in the previous recording of July 25, 2007. In two sessions, we recorded sounds with a custom click detector (Clicker45, Tachibana Electric Co. LTD., Tokyo, Japan), set between the amplifier (Reson EC6081) and video camera (Canon DM-IXYDVM5), using one channel of the video camera (16 bit, 44000-Hz sampling rate). The click detector converted each click to a 500- $\mu$ s rectangular signal with a voltage corresponding to the peak level of the click.

To assess the relationship between behaviour and sounds when the dolphins approached the introduced object or began to parallel pair-swim with other individuals, the sounds, position, posture, and swimming speed of the approaching dolphin were recorded for 3-5 s until it reached the object or other individual. Parallel pair-swimming is a behaviour in which two dolphins swim side by side in close $(<0.5 \mathrm{~m})$ proximity without body contact (Sakai et al., 2013).

Sounds produced at the onset of social behaviour (flipper rubbing) were recorded for $5 \mathrm{~s}$ before dolphins engaged in parallel pair-swimming initiated flipper rubbing. Flipper rubbing is a behaviour in which one dolphin rubs the other dolphin with its flipper (Sakai et al., 2006).

Although sounds could not be attributed to specific individuals in the July 25 data because the recording was made with a single hydrophone, those recorded December 27-28 were attributed based on the direction and position of all individuals relative to the hydrophone in the video records. In the analysis of sound and behaviour when an object was introduced to the tank, only sounds thought to be produced by the dolphin approaching the 
183 object were analysed; i.e. we considered only those recorded when no other

184 dolphins in the tank directed their heads toward the object.

185

\section{2.3. Sound analysis}

187 All sound records on July 25 and December 27-28 were analysed using the 188 Igor Pro ver.6 software (Wave Metrics Incorporated, Oregon, US) and Adobe

189 Audition 3.0 software (Adobe Systems Incorporated, California, US). Sound 190 spectrograms of all sounds with a good signal-to-noise ratio from July 25 191 were generated using the fast Fourier transform (FFT) algorithm, with FFT 192 length of $256,100 \%$ frame size, and a rectangular window. The sound 193 frequency with maximum energy (peak frequency) in each click was 194 analysed using Adobe Audition 3.0. Inter-click interval (ICI) is the interval 195 between the envelope peaks of consecutive clicks. We measured ICI using a 196 program that we made in Igor Pro. In this analysis, we eliminated any ICIs < $1970.5 \mathrm{~ms}$ as they were most likely caused by reflection from the tank walls or 198 water surface. Hatakeyama (1988) reported that the minimum ICI of a 199 captive Commerson's dolphin was $2.9 \mathrm{~ms}$; Kamminga and Wiersma (1981) 200 also reported that the average ICI of a captive Commerson's dolphin was $>2$ $201 \mathrm{~ms}$ (500 pulses/s) and that the minimum ICI of a captive harbour porpoise 202 was $1.0 \mathrm{~ms}$ (Clausen et al., 2010). All statistical analyses in this study were 203 conducted using Igor Pro. 
205

206

207

208

209

210

211

212

213

214

215

216

217

218

219

220

221

222

223

224

225

226

227

228

229

230

231

232

233

234

235

236

237

238

\section{Results}

All recorded sounds were ultrasonic pulses (clicks). In all, 114,590 pulses were recorded during 270 min from three individuals on July 25, 2007 and 227,910 pulses during 90 min from four individuals on December 27-28, 2007. Two types of pulse sound with different peak frequencies were recorded. The peak frequencies of each type were $129.4 \pm 4.9 \mathrm{kHz}$ (mean $\pm \mathrm{SD}$, $\mathrm{n}=30,87.1 \%$ of recorded pulses $)$ and $113.0 \pm 6.0 \mathrm{kHz}(\mathrm{n}=30,11.9 \%$ of recorded pulses), respectively.

Figure 3 shows the distribution of ICIs measured for all clicks recorded on July 25, 2007. Ninety-six percent of the measured ICIs were $<$ $100 \mathrm{~ms}$ (Fig. 3, mean ICI $=35.16 \pm 30.81 \mathrm{~ms}$ ). Based on this result, we defined a click-train as a group of sequential pulses separated from other pulses by an ICI $>100 \mathrm{~ms}$. Most of the recorded pulses (94.5\%) were produced as click-trains, sequences of several clicks ( $>5$ pulses) with relatively short ICIs, and 5.5\% were produced as single pulses or very short click-trains with 2-4 pulses. We removed single pulses or very short click-trains of $<4$ pulses from the analysis. A total of 6,449 click-trains were identified on July 25,2007 . The mean values $( \pm \mathrm{SD}$ ) of pulse number, ICI and duration of the click-trains were $43.9 \pm 32.9,26.5 \pm 20.0 \mathrm{~ms}$ and $769.2 \pm 700.6$ ms, respectively.

\subsection{Variation of click-trains}

We categorised click-trains by focussing on changes in mean ICI pattern, especially in the last part of the train (including $>5$ pulses from the last pulse), because it might reflect changes in target distance if the train was used for echolocation. Click-trains were divided into two groups based on mean ICI: those with very short mean ICIs $<4.0 \mathrm{~ms}$, and others with longer mean ICIs. Those with longer mean ICIs were further divided into three groups based on changing ICI pattern in the last part of the train. Thus, click-trains were categorised into the following four types (Fig. 4): Burst-pulse type, with very short $(<4.0 \mathrm{~ms}$ mean) and relatively constant ICI (Fig. 4-A); Decreasing type, with longer mean ICIs, in which ICI continuously decreased by $>2.0 \mathrm{~ms}$ in the last part of the train (Fig. 4-B); Increasing type, with longer mean ICI, in which ICI continuously increased 
239 by $>2.0 \mathrm{~ms}$ in the last part of the train (Fig.4-C); and Fluctuating type, with 240 longer mean ICI, in which ICI fluctuated in the train without a definite 241 continuous increase or decrease in the last part (Fig. 4-D).

242 The parameters of each type of click-train are shown in Table 1. 243 Only clear click-trains were used for this analysis because the dolphins often 244 emitted sounds simultaneously, confounding assessment. The mean ICI 245 differed significantly among these types (Kruskal-Wallis test: $\mathrm{H}=69.61, P<$ 246 0.001). It was highest in the Increasing type $(31.6 \mathrm{~ms})$, followed by the 247 Fluctuating type $(29.6 \mathrm{~ms})$, the Decreasing type $(25.0 \mathrm{~ms})$, and the 248 Burst-pulse type (3.5 ms).

249 The mean click-train duration was longest in the Fluctuating type 250 (1344.3 ms) and shortest in the Burst-pulse type (458.9 ms), though 251 significant differences were observed only between the Fluctuating type and 252 each of the other types (Kruskal-Wallis test, $\mathrm{H}=61.84, P<0.001$ ). The range 253 and standard deviation of click-train duration were also largest in the 254 Fluctuating type and smallest in the Increasing type.

255 The change in click-train ICI (maximum - minimum) was largest 256 in the Fluctuating type $(62.7 \pm 19.2 \mathrm{~ms})$ and smallest in the Burst-pulse type. 257 The change in ICI and the duration of continuous ICI change observed 258 during the last part of the train were $25.0 \pm 14.3 \mathrm{~ms}$ and $409.9 \pm 240.2 \mathrm{~ms}$ in 259 the Decreasing type and $36.0 \pm 18.3 \mathrm{~ms}$ and $347.6 \pm 201.04 \mathrm{~ms}$ in the 260 Increasing type, respectively.

Figure 5 shows the frequency (number/min/dolphin) and proportion 262 (percent) of each click-train type in the sounds recorded on July 25, 2007. 263 The Fluctuating (3.7/min/dolphin) and Decreasing (2.7/min/dolphin) types 264 were recorded more frequently than were the other types. The Increasing 265 type was the least common (0.4/min/dolphin, Fig. 5).

\subsection{Relationship between behaviour and click-train type}

268 Figure 6 shows the change in the frequencies (number/min/dolphin) of each 269 click-train type observed when a dolphin approached and then left a newly 270 introduced object ( $\mathrm{n}=165,90 \mathrm{~min}$ in total). The dolphins typically swam in a counter-clockwise routine course near the wall, but after the object was introduced, they often changed course to approach it repeatedly (Fig. 1). 
273 Clicks trains were recorded in 156 of 165 approaching-and-leaving episodes

274 (94.5\%; no or few isolated pulses were recorded in the remaining 5.5\%). The

275 frequency of the Decreasing type increased during the approach to the object 276 but decreased suddenly as the dolphin passed (Fig. 6). The Burst-pulse type 277 increased suddenly when the dolphin reached a position immediately in 278 front of the object, and was recorded in 50 of 165 episodes. When the 279 Burst-pulse type was recorded, the dolphin often bent its head toward the 280 object (43 of 50 episodes, $86 \%$ ) By contrast, when the focal dolphin was approaching the newly introduced target, the frequency of the Fluctuating and Increasing types did not change markedly, though the Fluctuating type seemed to decrease slightly after the dolphin passed.

The frequency of the Decreasing type during approach 285 (14.7/min/dolphin) was significantly higher than normal $(2.6 / \mathrm{min} /$ dolphin, 286 the mean value of all recording sessions on 25 July, 2007, Fig. 5) (Wilcoxon test, $\left.P=6.61 \mathrm{E}^{-20}\right)$. That of the Burst-pulse type $(9.2 / \mathrm{min} /$ dolphin $)$ was also 288 significantly higher than the baseline level (1.3/min/dolphin) (Wilcoxon test, $\left.289 P=1.25 \mathrm{E}^{-13}\right)$. The frequency of the Fluctuating type during the approach 290 (10.7/min/dolphin) was significantly higher than the baseline 291 (3.7/min/dolphin) (Wilcoxon test, $\left.P=4.93 \mathrm{E}^{-09}\right)$, while that of the Increasing 292 type (0.3/min/dolphin) was slightly lower (vs. $0.4 / \mathrm{min} /$ dolphin) but not 293 statistically different (Wilcoxon test, $P=0.53$ ).

Figure 7 shows the change in the frequency (number/min/dolphin) of each sound type when approaching another individual, and during parallel pair-swimming $(\mathrm{n}=44,220 \mathrm{~s}$ in total) thereafter. The frequencies of the

298 Increasing and Decreasing types increased during the approach to the other 299 dolphin, and decreased before the dolphins took up typical positions for 300 parallel pair-swimming. After starting parallel-pair swimming, the 301 frequency of the Increasing type increased again for about $2 \mathrm{~s}$, and then 302 decreased. By contrast, the Decreasing type gradually decreased after the 303 two dolphins started parallel-pair swimming. The frequency of the 304 Fluctuating type decreased gradually during the approach, and increased again gradually after the dolphin reached its partner and began parallel-pair swimming. The Burst-pulse type increased during the approach until 
307 parallel pair-swimming commenced, and decreased again thereafter. 308 However, the change of frequency in Fig. 7 was unclear, probably because 309 the sound-emitting dolphin could not be identified and sounds from other 310 dolphins were included in the analysis for Fig. 7.

The frequencies (number/min/dolphin) of the Increasing and

312 Fluctuating types during the approach were significantly higher than the 313 mean value of the entire recording (Fig. 8, Wilcoxon test, $P=0.00039$ and $P=$ $\left.3141.10 \mathrm{E}^{-10}\right)$; the frequencies of the Increasing (2.3/min/dolphin) and 315 Fluctuating (9.7/min/dolphin) types were 5.7- and 2.6-fold higher than the 316 baseline level (0.4/min/dolphin and 3.7/min/dolphin), respectively.

Finally, we compared the frequency (number/min/dolphin) of each 319 sound type between the two approach behaviours: approach to a new object $320 \quad(n=165)$ and approach to another individual $(n=44)($ Fig. 9).

321 The frequencies (number/min/dolphin) of the Decreasing (14.7 $322 / \mathrm{min} /$ dolphin) and Burst-pulse (9.2/min/dolphin) types during the approach 323 to the object were significantly higher than those during the approach to the 324 other individual $(8.4 / \mathrm{min} /$ dolphin and $2.3 / \mathrm{min} /$ dolphin; Wilcoxon test, $P=$ $3253.72 \mathrm{E}^{-21}$ and $P=9.04 \mathrm{E}^{-10}$, respectively), while the frequency of the 326 Increasing type (2.3/min/dolphin) was significantly higher when approaching 327 the other individual than when approaching the object $(0.3 / \mathrm{min} / \mathrm{dolphin}$; 328 Wilcoxon test, $P=0.00030)$. We observed no significant difference in the 329 Fluctuating type (Wilcoxon test, $P=0.64$ ).

$330 \quad$ During parallel-pair swimming before flipper rubbing behaviour (n $331=14,70 \mathrm{~s}$ in total), the frequencies (number/min/dolphin) of the Increasing $332(2.3 / \mathrm{min} /$ dolphin) and Fluctuating (8.6/min/dolphin) types were significantly 333 higher than the mean values of the entire recording $(0.4 / \mathrm{min} / \mathrm{dolphin}$ and $3343.7 / \mathrm{min} /$ dolphin, Wilcoxon test, $P=0.019$ and $P=6.86 \mathrm{E}^{-03}$ respectively). We 335 found no significant difference in the frequency of the Decreasing 336 (2.6/min/dolphin) or Burst-pulse (1.4/min/dolphin) types compared with the 337 mean values of the entire recording $(3.2 / \mathrm{min} / \mathrm{dolphin}$ and $1.8 / \mathrm{min} / \mathrm{dolphin}$, respectively; Wilcoxon test, $P=0.91$ and $P=0.88$ ). 


\section{Discussion}

\subsection{Variation in recorded sounds}

344 In this study, we recorded only ultrasonic click sounds (ca. 113-130 kHz in 345 peak frequency), with no whistles or audible sounds. In previous studies, low 346 frequency clicks (ca. $1.0-6.0 \mathrm{kHz}$ ) were also reported in captive Commerson's 347 dolphins (Dziedzic and De Buffrenil, 1989; Hatakeyama et al., 1988; Shochi 348 et al., 1982; Watkins and Schevill, 1980). Some of these low-frequency clicks were audible to researchers, though not recorded frequently. These click-trains, or cry sounds, include audible low-frequency clicks with very short ICIs, similar to the Burst-pulse type (Shochi et al., 1982). Cry sounds are composed of high (116-133 kHz) and low (1-7 kHz, audible to humans)

353 frequency clicks (Dziedzic and De Buffrenil, 1989; Shochi et al., 1982).

354 Watkins et al (1977) defined the cry sound as a pulse series at a repetition 355 rate rapid enough to produce tonal sounds. Shochi et al. (1982) also reported 356 short clicks in the ultrasonic range superimposed on low-frequency pulses $357(1-2 \mathrm{kHz})$ audible to humans only when captive dolphins approached within 358 20-30 $\mathrm{cm}$ of the hydrophone. The two signal components were always 359 synchronous. These reports suggest that the cry sounds were the 360 low-frequency components of clicks caused by high repetition-rate ultrasonic 361 pulses. Therefore, the cry sounds could have been the same sound type as the 362 Burst-pulse type in the present study. The peak frequency of the 363 high-frequency component (116-133 kHz) of the cry sound (Dziedzic and De 364 Buffrenil, 1989; Shochi et al., 1982) was similar to that of the Burst-pulse 365 type (113-130 kHz). Likewise, the peak frequencies of high-frequency clicks 366 recorded in this study $(130 \mathrm{kHz})$ were similar to those reported by previous 367 studies on wild $(133 \mathrm{kHz})$ and captive $(116-133 \mathrm{kHz})$ Commerson's dolphins 368 (Evans et al., 1988; Kamminga and Wiersma, 1981; Kyhn et al., 2010).

\subsection{Function of each click-train type}

371 4.2.1 Decreasing type: recognition of a target as it is approached

372 The ICI pattern of the Decreasing type click-train (Fig. 4), where ICI 373 decreased in the last part of the train, suggests that it is used for 374 echolocation when the dolphin is approaching a target, as the ICI of 
375 echolocation clicks may reflect the distance between the dolphin and its 376 target (Au, 1993). Such a rapid decrease in ICI is known as the "approach 377 phase" in the echolocation sounds of harbour porpoise and in bats 378 intercepting a target (Tian and Schnitzler, 1997; Verfuss et al., 2009). The 379 fact that the frequency (number/min/dolphin) of the Decreasing type of click 380 train increased during the approach to an object newly introduced to the 381 tank (a probable target), and when a dolphin approached another individual 382 (Figs. 6, 7), supports this view. However, the change in frequency of the 383 Decreasing type in Fig. 7 was not as clear as that in Fig. 4, probably because 384 the sound-emitting dolphin could not be identified and sounds from other 385 dolphins were included in the analysis for Fig. 7. Shochi et al. (1982) and 386 Watkins and Schevill (1980) also observed that ICI decreased in the 387 click-trains of captive Commerson's dolphins when the dolphins approached 388 a fish or other targets, and suggested that the sounds were used in target 389 echolocation. Similar ICI-decreasing click-trains were reported in wild 390 Hector's dolphins approaching a hydrophone (Dawson, 1991).

391 In captive harbour porpoises, Clausen et al. (2010) reported similar 392 click-trains in a mother-calf pair when they engaged in aggressive or 393 encounter behaviours ("contact call behaviour") in which the dolphins 394 approached each other. These click-trains were characterised by increasing 395 repetition rate (rapid decrease of ICI), changing from 20 to 800 clicks/s (50 to $3961.2 \mathrm{~ms}$ ICI). This is similar to the ICI range of our Decreasing type 397 click-trains (89.5 to $1.1 \mathrm{~ms}$ ICI). It is possible that the harbour porpoise 398 click-trains were also used for echolocation, though the results of Clausen et 399 al. (2010) suggest that these sounds were used for communication.

401 4.2.2 Burst-pulse type: short-range target recognition

402 The fact that most of the Burst-pulse type click-trains were emitted toward 403 the object newly introduced to the tank from a distance of $\sim 0.5 \mathrm{~m}$ suggests 404 that they were used for close proximity echolocation. Moreover, we recorded 405 a significant increase in the Burst-pulse type when an object was newly 406 introduced.

However, some "lag time" is thought to be required for the neuronal 408 process of echolocation, and many of the ICIs in the Burst-pulse type (mean 
$4093.5 \pm 1.1 \mathrm{~ms})$ may have been shorter than the time required. Lag time is 410 defined as the difference in time between the two-way travel time of the 411 sound to the target and the ICI (Au and Cranford, 2000). Although the lag 412 time of Commerson's dolphin is still not known, the minimum lag time 413 estimated for the Atlantic bottlenose dolphin (family Delphinidae, the same 414 as Commerson's dolphin) was reported as $2.5 \mathrm{~ms}$ (Au et al., 1974). However, 415 in the harbour porpoise (family Phocoenidae), a small species such as 416 Commerson's dolphin, the minimum lag time was reported as $1.5 \mathrm{~ms}$ 417 (Verfuss et al., 1999). Furthermore, the lag time of bottlenose dolphins 418 decreased from 15.4 to $2.5 \mathrm{~ms}$ as the distance to the target decreased from 4191.4 to $0.4 \mathrm{~m}$ (Evans and Powell 1967). Assuming that the lag time of 420 Commerson's dolphin was similar to those of the bottlenose dolphin or 421 harbour porpoise, most of the Burst-pulse type ICIs were longer than the lag 422 time. Thus, it is possible that the Burst-pulse type could have an 423 echolocation function in Commerson's dolphin.

424 Kamminga and Wiersma (1981) also recorded a burst of sonar 425 signals (<2-ms ICI, 500 clicks/s repetition rate, 4 -s train duration) similar to 426 the Burst-pulse type when captive Commerson's dolphins approached and 427 inspected newly introduced hydrophones at very short range. The reported 428 mean ICI $(<2 \mathrm{~ms})$ was close to that observed for the Burst-pulse type $(3.5 \pm$ $4291.8 \mathrm{~ms})$, although the mean train duration $(4 \mathrm{~s})$ was not $(458.9 \pm 304.4 \mathrm{~ms})$. 430 Such bursts of sonar signals emitted toward objects in close proximity were 431 also recorded in other dolphin species (e.g. bottlenose dolphin, white whale), 432 and the possibility of their function in echolocation with ICIs less than the 433 lag time has been discussed (Turl and Penner, 1989).

434 Burst-pulse sounds have been observed during aggressive social 435 interactions as well as approaching behaviour in NBHF species and other 436 odontocetes, and their function in both communication and echolocation in 437 these species is suspected. Harbour porpoise also emits a cry sound with a 438 mean ICI of $3.7 \mathrm{~ms}$. Harbour porpoises use this cry sound during aggressive 439 behaviour toward other dolphins (Clausen et al., 2010; Nakamura et al., 440 1998). However, we did not observe such behaviour or any remarkable 441 responses of other dolphins to the Burst-pulse type in Commerson's dolphin, 442 though Watkins and Schevill (1980) reported that cry sounds of captive 
443 Commerson's dolphins seemed to elicit responses from others in the same 444 tank.

The Burst-pulse type was recorded not only when the dolphins 446 faced a newly introduced object in close proximity but also when no obvious 447 echolocation targets were present, other than the tank walls and other 448 dolphins. However, we observed no notable behaviours oriented to those 449 targets (e.g. head bending toward the objects) (Fig. 10). The Burst-pulse type 450 also increased immediately after a dolphin approached another dolphin and 451 initiated parallel-pair swimming, though we could not identify the dolphin 452 emitting the sound. These facts suggest that some of the Burst-pulse type 453 click-trains were used for other functions, such as calls to swim together. 454 However, this increase may also have been due to increased short-range 455 echolocation of the partner when pair swimming. Although Burst-pulse type 456 click-trains aimed at the newly introduced object might also have been alarm calls, we did not observe any obvious reactions in other dolphins when they 458 were emitted. Thus, our results suggest that the Burst-pulse type sounds of 459 Commerson's dolphin in captivity were used as short-range sonar rather 460 than for communication. The fact that the reported cry sounds of 461 Commerson's dolphins were recorded for only a few days after the dolphins 462 were moved to a new tank (a novel environment with many targets for them 463 to inspect) also supports this view, as a prominent increase in the 464 Burst-pulse type was recorded when an object was newly introduced.

\section{4.2.3 Fluctuating type: sensing targets at various ranges}

467 In the Fluctuating type click-trains, ICI fluctuates irregularly over a wide 468 range. If this type of click-train were used for echolocation, the target 469 distance would also change irregularly and widely, because ICI reflects the 470 distance between the dolphin and the target, including the lag time ( $\mathrm{Au}$, 471 1993). Thus, the irregular change of ICI suggests that the Fluctuating type 472 was used for scanning a wide range of space in front of the dolphin rather 473 than for echolocating a particular target. Hatakeyama et al. (1988), who 474 studied captive Commerson's dolphins in a Japanese aquarium, reported 475 that clicks with widely varying ICI (similar to the Fluctuating type) 476 increased when the aquarium lights were turned off, suggesting that they 
477

478

479

480

481

482

483

484

485

486

487

488

489

490

491

492

493

494

495

496

497

498

499

500

501

502

503

504

505

506

507

508

509

510

were used for echolocation.

The Fluctuating type was the most frequently recorded sound type, accounting for about half of all recorded click-trains. The Fluctuating type became significantly more frequent than the baseline level when approaching both the introduced object and other dolphins prior to parallel-pair swimming. This suggests that the Fluctuating type increased during active behaviours, though it decreased as other sound types increased just before and after dolphins started parallel-pair swimming (Fig. 7). Shochi et al. (1982), who studied captive Commerson's dolphins, reported that the repetition rate of clicks varied widely (like the Fluctuating type) when the dolphin was resting in the water, motionless, or swimming slowly, though they did not provide precise data. This observation suggests that the dolphins produce Fluctuating-type click-trains even when inactive. The frequent use of this sound type, in both active and inactive states, suggests that it is used for forward scanning; e.g. to avoid collision, to find fish, or to investigate the surroundings (Akamatsu et al., 2010).

Akamatsu et al. (1998) compared the clicks of Baiji, Finless porpoise, and Bottlenose dolphin between captive and wild individuals. They reported that in all studied species, most of the click-trains from the wild dolphins showed irregular ICI change without monotonous increment or decrement, like the Fluctuating type, while those from captive dolphins often showed monotonous ICI decrement, similar to the Decreasing type. Furthermore, these latter sounds were used for echolocation by dolphins approaching targets such as tank walls. Although Akamatsu et al. (1998) did not discuss the function of click-trains with irregular ICIs, their results suggest that the Fluctuating type is not used for echolocating a particular target, as there are fewer target objects in open water than in aquarium tanks. Dolphins in open water may scan their surroundings more frequently than those in aquarium tanks. If so, the frequent use of this sound type in open water also supports our view.

\subsubsection{Increasing type: possibly for social communication}

The changing pattern of ICI in the Increasing type, in which ICI increased in the last part of the train, suggests that the target distance increased during 
511 the train if it was used for echolocating a particular target object. Such an 512 echolocation target (to which the distance from the emitting dolphin 513 increased with time) was largely absent from our study, with the potential 514 exception of other dolphins and the tank walls, because dolphins did not 515 swim backwards. The target distance could increase if the targeted dolphin 516 swam away from the emitting dolphin. It could also increase as the angle 517 between emitted clicks and the targeted tank wall changed as the dolphin 518 changed course at the tank corners.

519 The frequency (number/min/dolphin) of Increasing-type click-trains 520 increased when a dolphin approached another dolphin and began 521 parallel-pair swimming, while they were rarely emitted when approaching a newly introduced object. They also increased during parallel-pair swimming just before flipper rubbing. These facts suggest that the Increasing type is not used for echolocation. It is difficult to explain these results if we assume that the Increasing-type click-trains were used for echolocating the tank walls, as we observed no obvious change in the emitting dolphin's swimming course. Rather, these facts suggest that the Increasing type was used for initiating social behaviour in which the cooperative movements of two dolphins are required.

There are no previous reports on click trains corresponding to the 531 Increasing type in Commerson's dolphin. In Hector's dolphin, however, 532 Dawson (1991) recorded click trains similar to the Increasing type. He 533 compared the sound types between social and non-social contexts to examine 534 the possibility that the dynamics of the click rate (increasing, constant, and 535 decreasing) carry social meaning, but detected no significant differences. 536 Click-trains similar to the Increasing type were also found in a report on 537 harbour porpoises (Clausen et al., 2010), although it did not describe these 538 click-trains precisely.

We examined the potential functions of each click-train type based on the results of rather preliminary observations in which identification of the sound-emitting dolphin was difficult. More precise studies on the 542 relationship between these click-train types and behaviour are needed to clarify the functions of the various click-train types. 


\section{Acknowledgments}

546 We are grateful to the members of the Toba Aquarium, Ms. Masako Yano,

547 Mr. Yoshihiro Ishihara, and Mr. Masami Furuta for their kind support. We

548 also thank the members of the Kohshima Laboratory. This work was partly

549 supported by the Excellent Graduate Schools program of MEXT, Japan for

550 YY, and by JSPS KAKENHI Grant Number 23220006 to TM.

551

\section{Figure Titles (Captions) \& Legends}

553 Fig. 1

554 Title: Recording setting.

555 Legend: Two video cameras and one hydrophone set in the main pool. All

556 dolphins usually swam the course indicated by the grey line. Dotted lines are examples of swimming courses when approaching and leaving the object.

558

559 Fig. 2

560 Title: Example of approaching dolphin to the introduced object, and the

561 hydrophone.

562 Legend: Frame from video camera A (Fig.1). The sounds of the dolphin were

563 recorded by the hydrophone underneath the object.

564

565 Fig. 3

566 Title: Histogram of all recorded Inter-click-intervals (ICI) on July 25, 2007.

567 Legend: The right axis shows the ICI value and the left axis the

568 accumulation rate of all recorded ICIs. Ninety-six percent of measured ICIs

569 were $<100 \mathrm{~ms}$ (mean ICI $\pm \mathrm{SD}=35.16 \pm 30.81 \mathrm{~ms})$. The grey line indicates

570 the ICI cumulative frequency curve.

$572 \quad$ Fig. 4

573 Title: Click-train of each sound type.

574 Legend: X-axis: time line, Y-axis: ICI; Inter-Click-Interval (ms), SPL: Sound

575 Pressure Level (dB).

578 Title: The frequency and percentage of each click-train type. 
579 Legend: The numbers in the upper right are the percentages of all observed 580 trains.

581

582 Fig. 6

583 Title: Change in frequency of each click-train type when the dolphin was

584 approaching and leaving the object.

585 Legend: The frequency of the Decreasing type increased while approaching

586 the object, and the Burst-pulse type increased suddenly when the dolphin

587 reached a position immediately in front of the object.

588

589 Fig. 7

590 Title: Change in frequency of each click-train type while approaching

591 another individual.

592 Legend: The right y-axis indicates the number of Fluctuating type sounds.

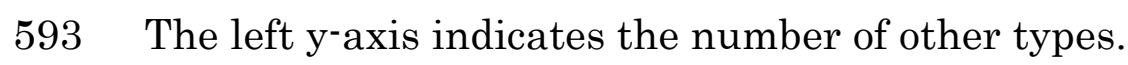

594

595 Fig. 8

596 Title: Frequency of each sound type while approaching another individual.

597 Legend: The frequencies of the Increasing (2.3/min/dolphin) and Fluctuating

$598(9.7 / \mathrm{min} /$ dolphin $)$ types were 5.7- and 2.6-fold higher than the baseline level

599 (0.4/min/dolphin and 3.7/min/dolphin), respectively.

600

601 Fig. 9

602 Title: Frequency of each click-train type during the approach to two different

603 targets.

604

605

606 Fig. 10

607 Title: A dolphin bending its head toward the introduced object.

608 Legend: Frame from video camera B (Fig. 1).

609

610 Table 1

611 Title: Characteristics of each click-train type

612 


\section{References}

614

615 Akamatsu, T., Wang, D., Nakamura, K., Wang, K., 1998. Echolocation range of captive and free-ranging baiji (Lipotes vexillifer), finless porpoise (Neophocaena phocaenoides), and bottlenose dolphin (Tursiops truncatus). J. Acoust. Soc. Am. 104, 2511-6.

620

Akamatsu, T., Wang, D., Wang, K., Li, S., Dong, S., 2010. Scanning sonar of rolling porpoises during prey capture dives. J. Exp. Biol. 213, 146-52.

Au, W., 1993. The sonar of dolphins. Springer. Chapter 7, pp.115-117, 134-135

Au, W.W., Cranford, T.W., 2000. Hearing by whales and dolphins. Springer. Chapter 9, pp.376-377.

625

Au, W.W., Kastelein, R.A., Rippe, T., Schooneman, N.M., 1999. Transmission beam pattern and echolocation signals of a harbor porpoise (Phocoena phocoena). J. Acoust. Soc. Am. 106, 3699-705.

Au, W.W.L., Floyd, R.W., Penner, R.H., Earl Murchison, A., 1974. Measurement of echolocation signals of the Atlantic bottlenose dolphin, Tursiops truncatus Montagu, in open waters. J. Acoust. Soc. Am. 56, 1280-1290.

Caldwell, M.C., Caldwell, D.K., 1971. Statistical evidence for individual signature whistles in the Pacific Whitesided Dolphin, Lagenorhynchus Obliquidens. Los Angeles Cty. museum Nat. Hist. Found.

Clausen, K.T., Wahlberg, M., Beedholm, K., Deruiter, S., Madsen, P.T., 2010. Click communication in Harbour Porpoises Phocoena Phocoena. Int. J. Anim. Sound its

Dawson, S.M., 1988. The high frequency sounds of free-ranging Hector s dolphins, Cephalorhynchus hectori. Rep. Int. Whal. Comm. 339-344.

Dawson, S.M., 1991. Clicks and Communication : The Behavioural and Social Contexts of Hector' s Dolphin Vocalizations 11.

Dziedzic, A., De Buffrenil, V., 1989. Acoustic signals of the Commerson's dolphin,

643 Evans, W.E., Awbrey, F.. Hackbarth, H., 1988. High frequency pulses produced by 644 free-ranging Commerson's dolphin (Cephalorhynchus commersonii) compared to 645 those of phocoenids. Biol. genus Cephalorhynchus 173-181. 
646 Hatakeyama, Y., Ishii, K., Soeda, H., Shimamura, T., 1988. Acoustic serveys on Commerson’s dolphin. Doc. Submitt. to Int. North Pacific Fish. Comm. Agency Japan, Tokyo, Japan 1 1-21.

Janik, V., Slater, P., 1998. Context-specific use suggests that bottlenose dolphin signature whistles are cohesion calls. Anim. Behav. 56, 829-838.

Kamminga, C., Wiersma, H., 1981. Investigations on cetacean sonar II. Acoustical similarities and differences in odontocete sonar signals. Aquat. Mamm. 8, 41-63.

Kamminga, C., Wiersma, H., 1982. Investigations on cetacean sonar. V. The true nature of the sonar sound of Cephalorhynchus commersonii. Aquat. Mamm. 9, 95-104.

Kyhn, L. a, Jensen, F.H., Beedholm, K., Tougaard, J., Hansen, M., Madsen, P.T., 2010. Echolocation in sympatric Peale's dolphins (Lagenorhynchus australis) and Commerson's dolphins (Cephalorhynchus commersonii) producing narrow-band high-frequency clicks. J. Exp. Biol. 213, 1940-9.

Madsen, P., Carder, D., Bedholm, K., Ridgway.S.H, 2005. Porpoise clicks from a sperm whale nose-Convergent evolution of $130 \mathrm{kHz}$ pulses in toothed whale sonars? Bioacoustics 15, 195-206.

Morisaka, T., 2012. Evolution of Communication Sounds in Odontocetes: A Review. Int. J. Comp. Psychol. 25, 1-20.

Morisaka, T., Connor, R.C., 2007. Predation by killer whales (Orcinus orca) and the evolution of whistle loss and narrow-band high frequency clicks in odontocetes. J. Evol. Biol. 20, 1439-58.

Nakamura, K., Akamatsu, T., Shimazaki, K., 1998. Threat clicks of captive harbor porpoises, Phocoena phocoena. Hokkaido University.

Sakai, M., Hishii, T., Takeda, S., Kohshima, S., 2006. Flipper Rubbing Behaviors in Wild Bottlenose Dolphins (Tursiops Aduncus). Mar. Mammal Sci. 22, 966-978.

Sakai, M., Morisaka, T., Iwasaki, M., Yoshida, Y., Wakabayashi, I., Seko, A., 
679 Tian, B., Schnitzler, H.-U., 1997. Echolocation signals of the greater horseshoe bat

680 (Rhinolophus ferrumequinum) in transfer flight and during landing. J. Acoust. Soc. 681 Am. 101, 2347-64.

682 Tougaard, J., Kyhn, L., 2010. sounds of hourglass dolphins (Lagenorhynchus cruciger)

683 are similar to the narrow band high-frequency echolocation sounds of the dolphin 684 genus Cephalorhynchus. Mar. Mammal Sci. 26, 239-245.

685 Turl, C.W., Penner, R.H., 1989. Differences in echolocation click patterns of the beluga 686 (Delphinapterus leucas) and the bottlenose dolphin (Tursiops truncatus). J. Acoust. $687 \quad$ Soc. Am. 86, 497-502.

688 Van Parijs, S.M., Corkeron, P.J., 2001. Vocalizations and Behaviour of Pacific 689 Humpback Dolphins Sousa chinensis. Ethology 107, 701-716.

690 Verfuss, U.K., Lee A, M., Hans-Ulrich, S., 1999. The echolocation behavior of the 691 harbor porpoise (Phocoena phocoena) during prey capture, in: Proceedings of the 692 13th Biennial Conference on the Biology of the Marine Mammals,Maui,The 693 Society for Marine Mammalogy.pp. 193-194.

694 Verfuss, U.K., Miller, L. a, Pilz, P.K.D., Schnitzler, H.-U., 2009. Echolocation by two 695 foraging harbour porpoises (Phocoena phocoena). J. Exp. Biol. 212, 823-34.

696 Watkins, W.A., Schevill, W.E., 1980. Characteristic features of the underwater sounds 697 of Cephalorhynchus commersonii. J. Mammal. 61, 738-739.

698 Watkins, W.A., Schevill, W.E., Best, P.B., 1977. Underwater sound of 699 chephalorhynchus heavisidii. J. Mammal. 316-320. 
Fig.1

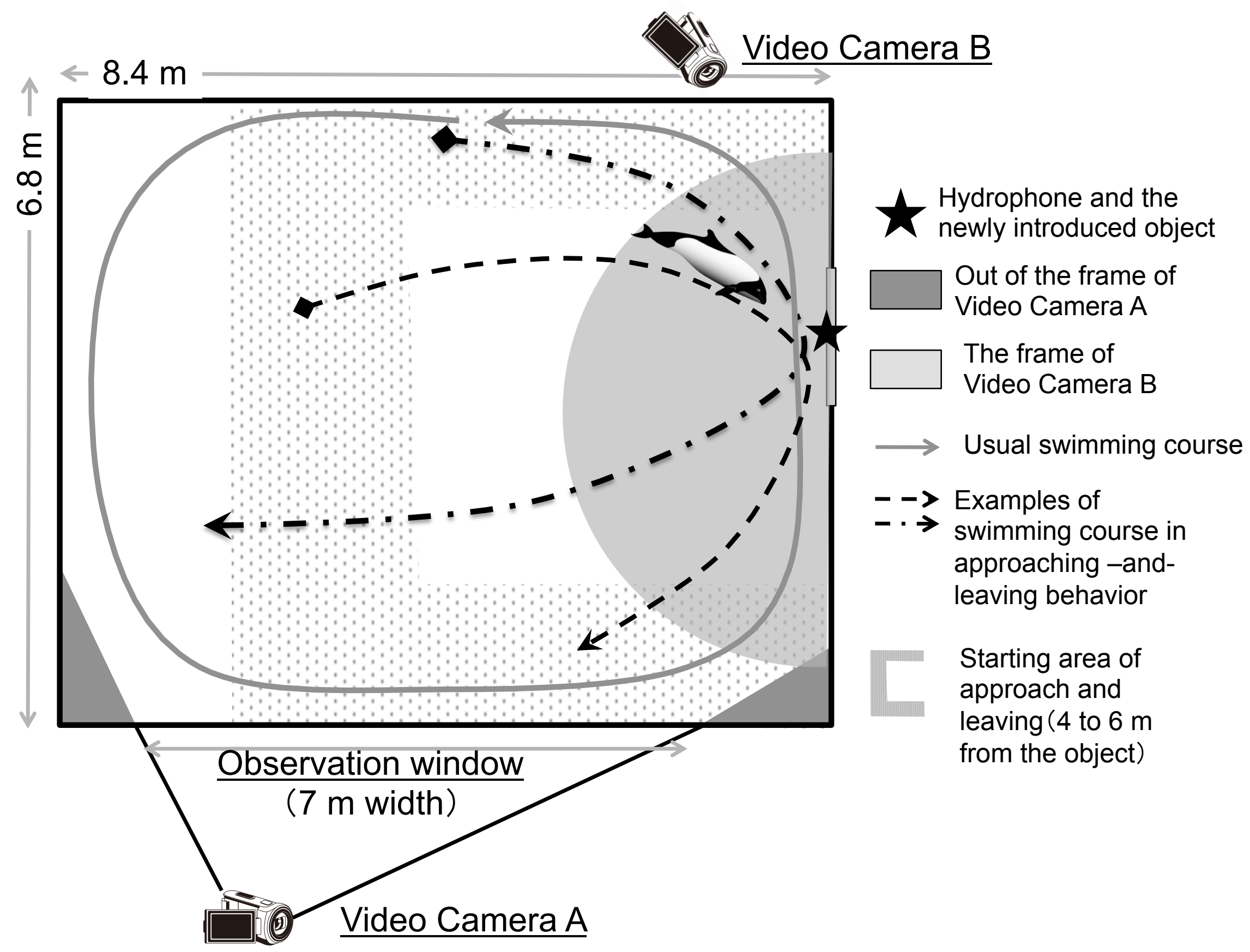


Fig.2

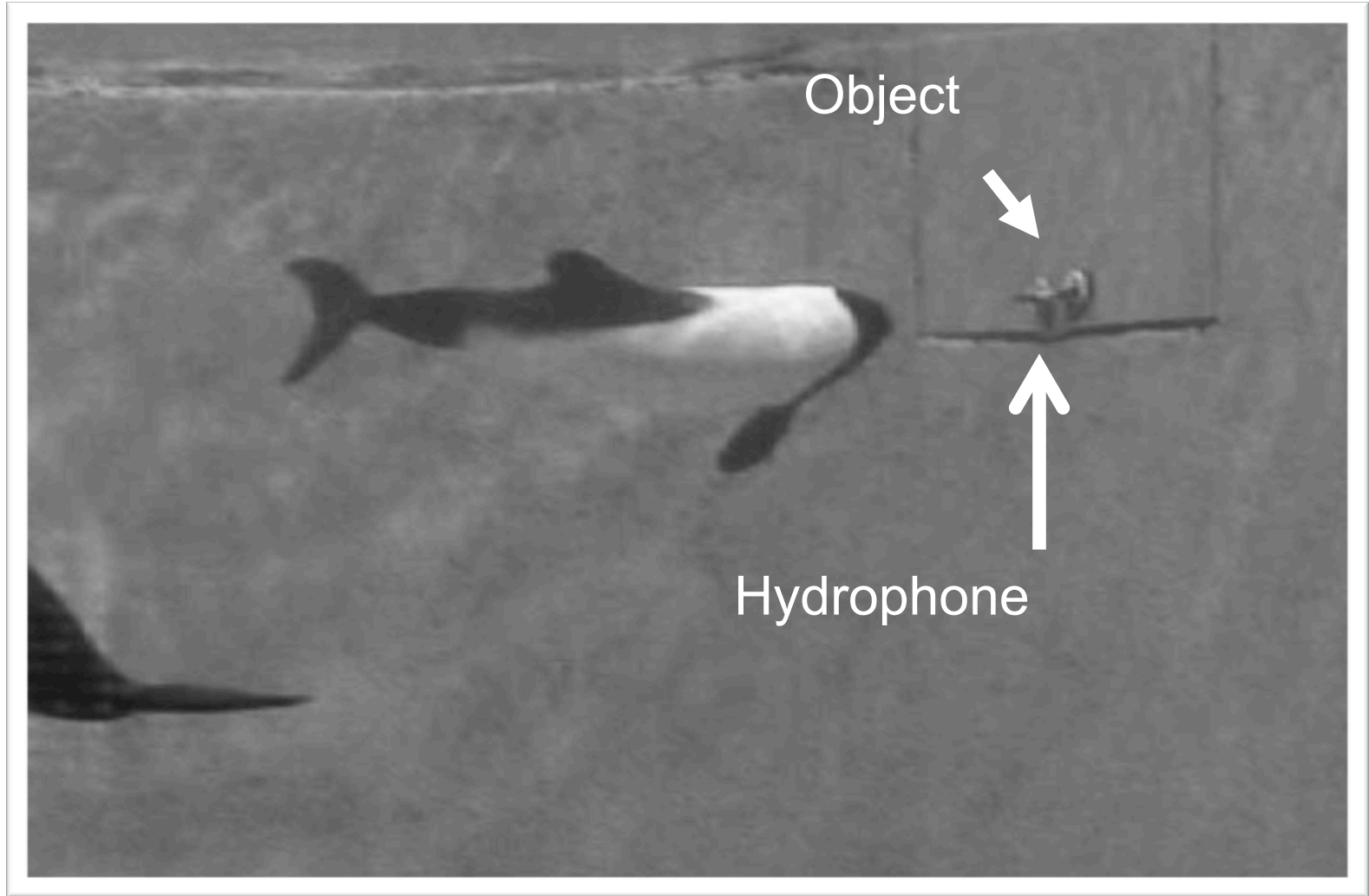


Fig.3

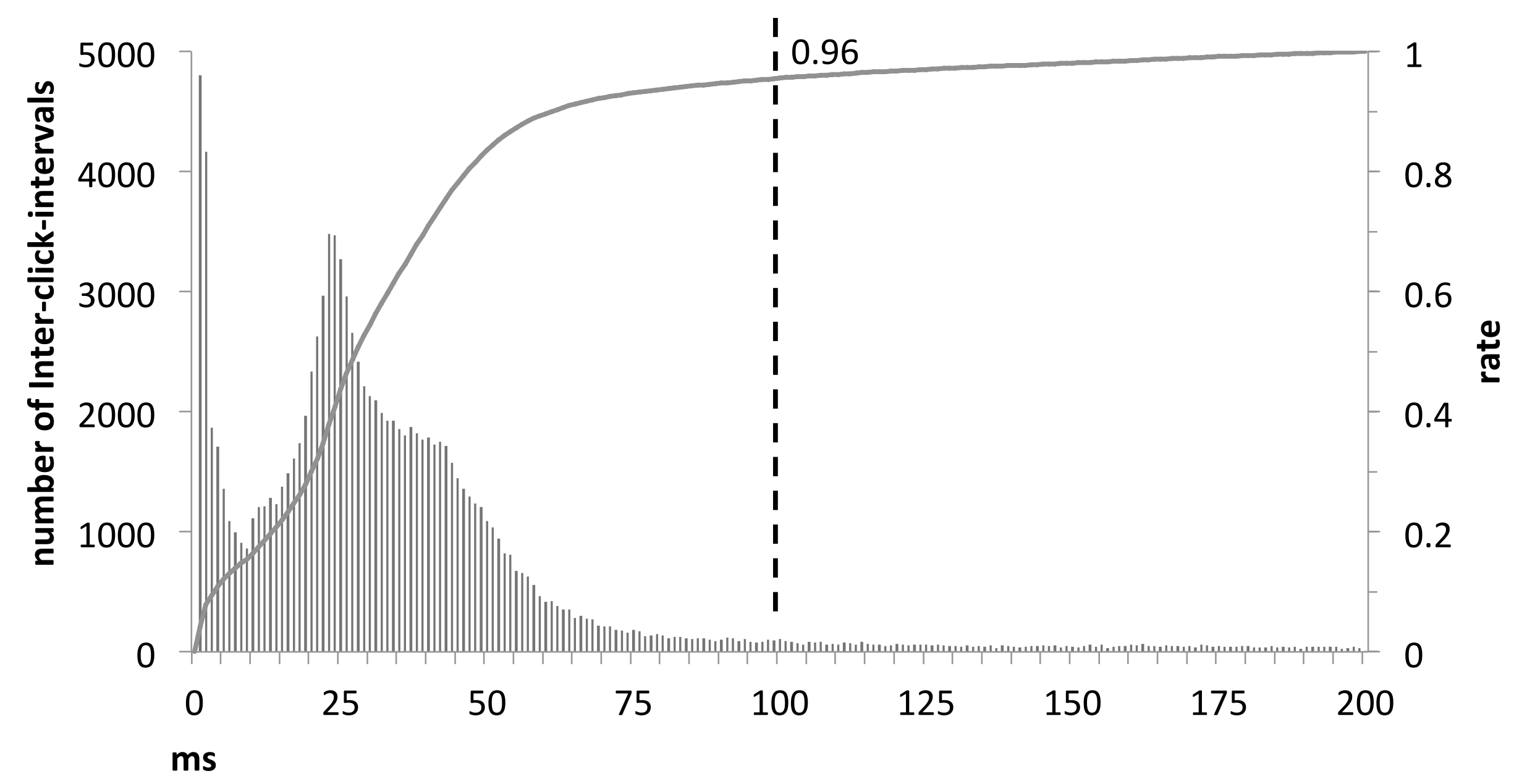


Fig.4

(A) Burst pulse type

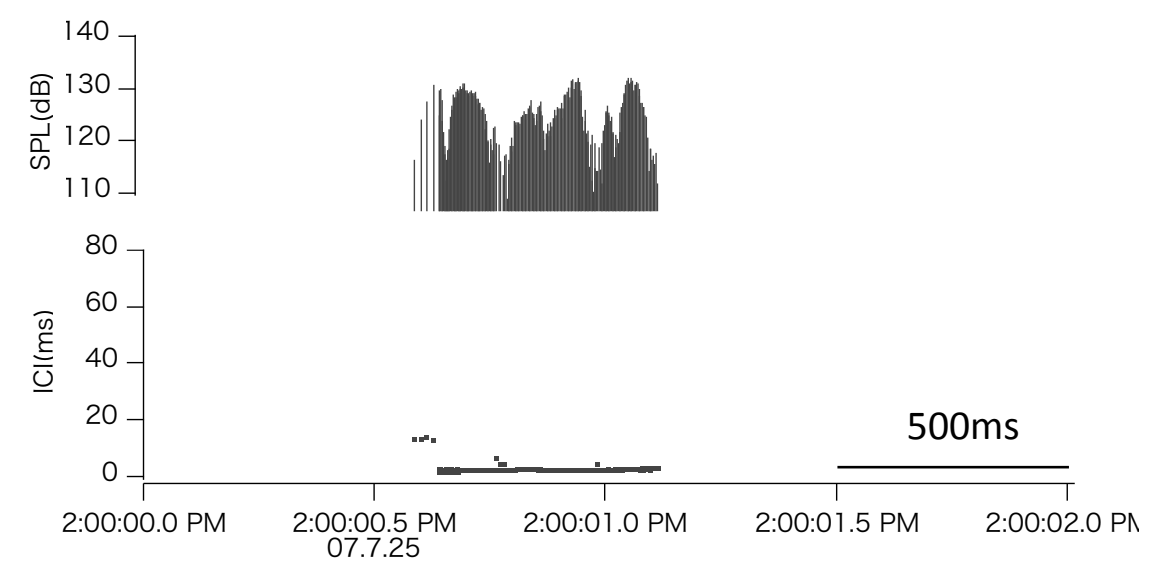

(C) Increasing type

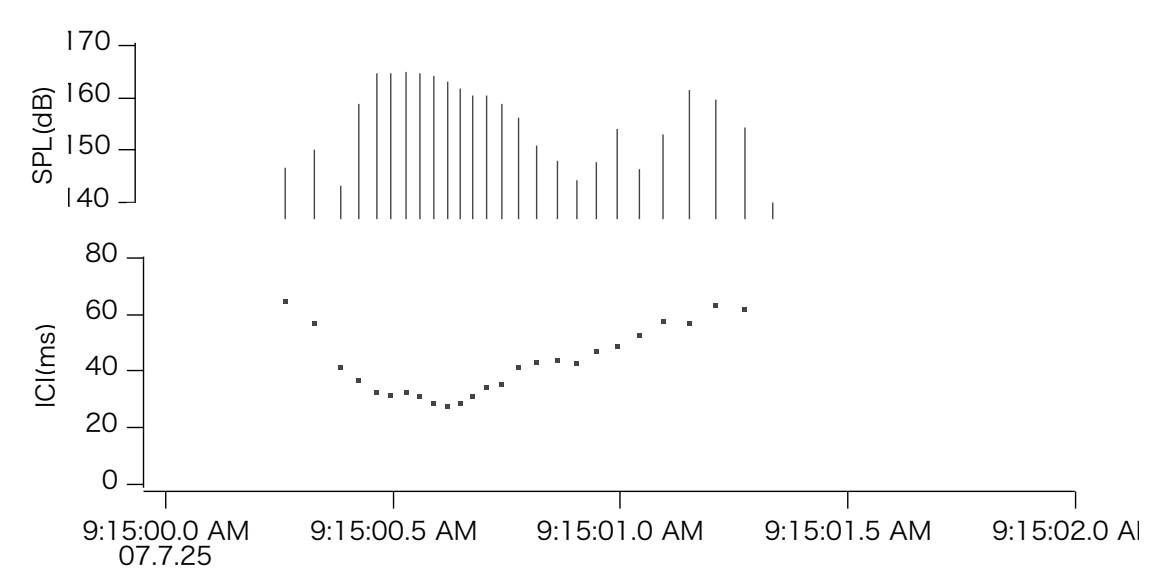

(B) Decreasing type

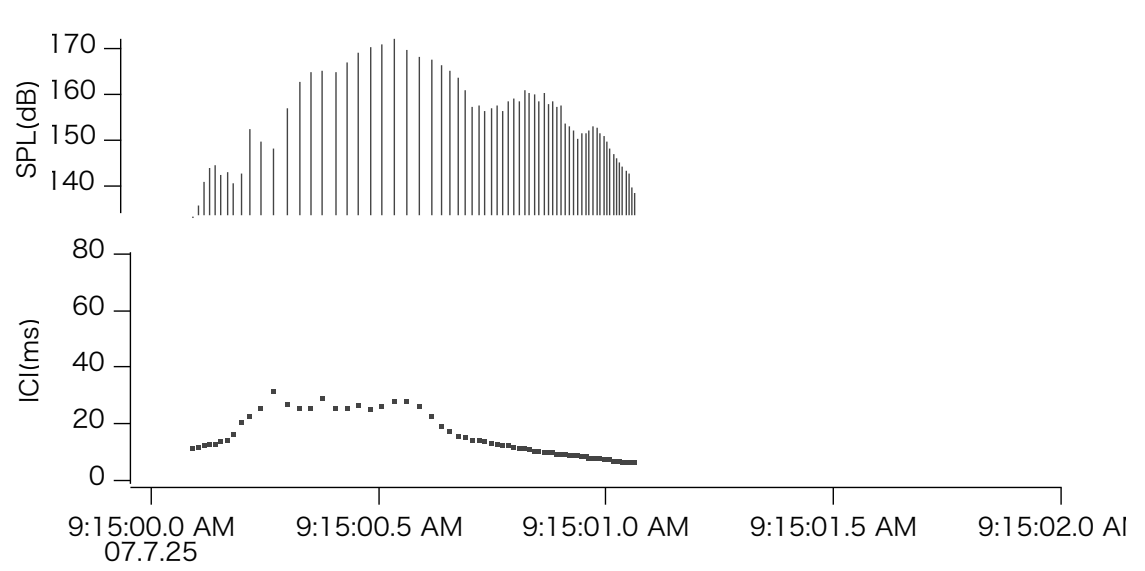

(D) Fluctuating type

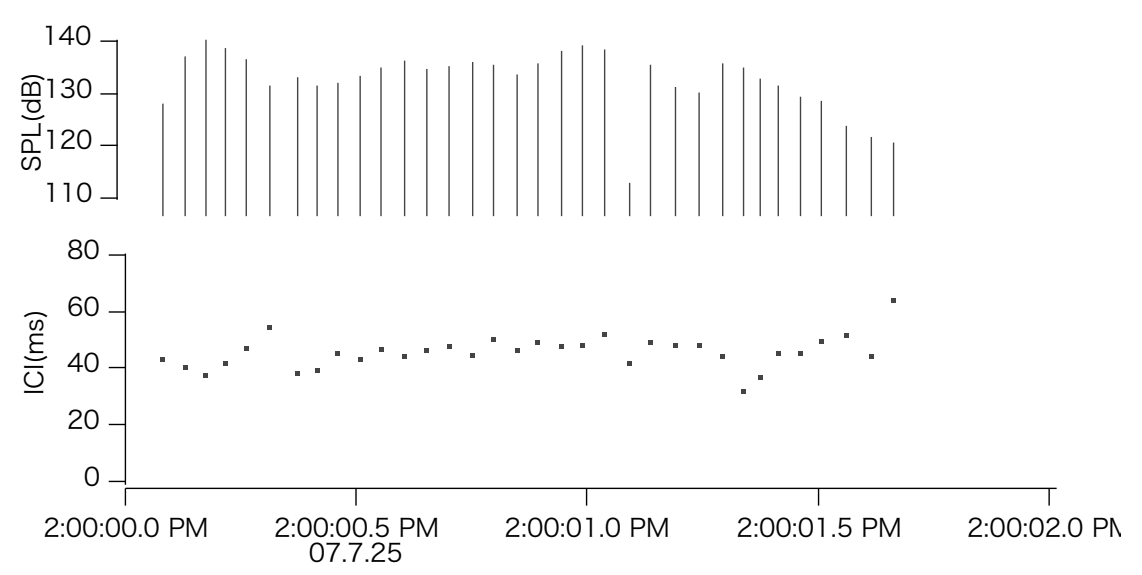


Fig.5

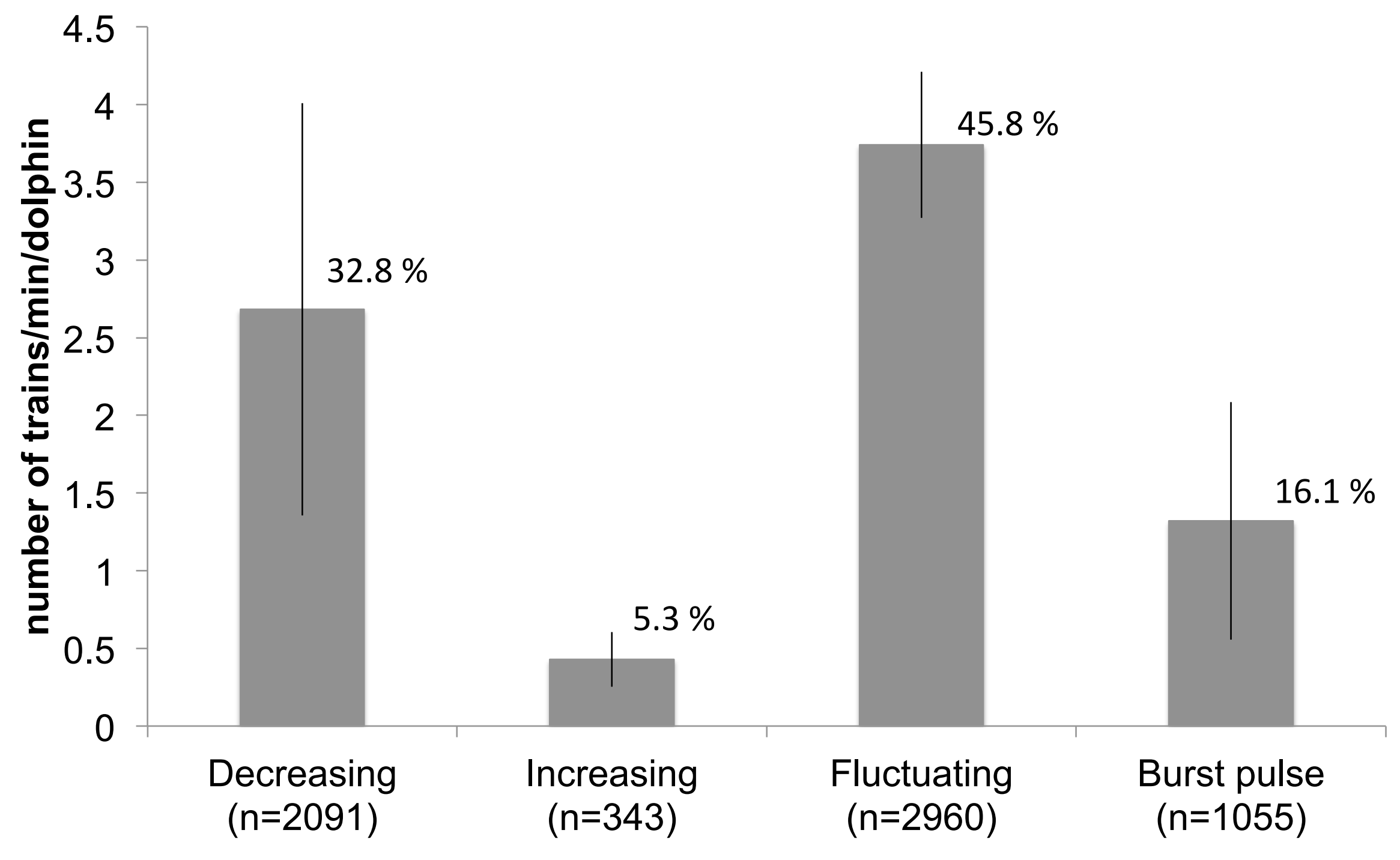




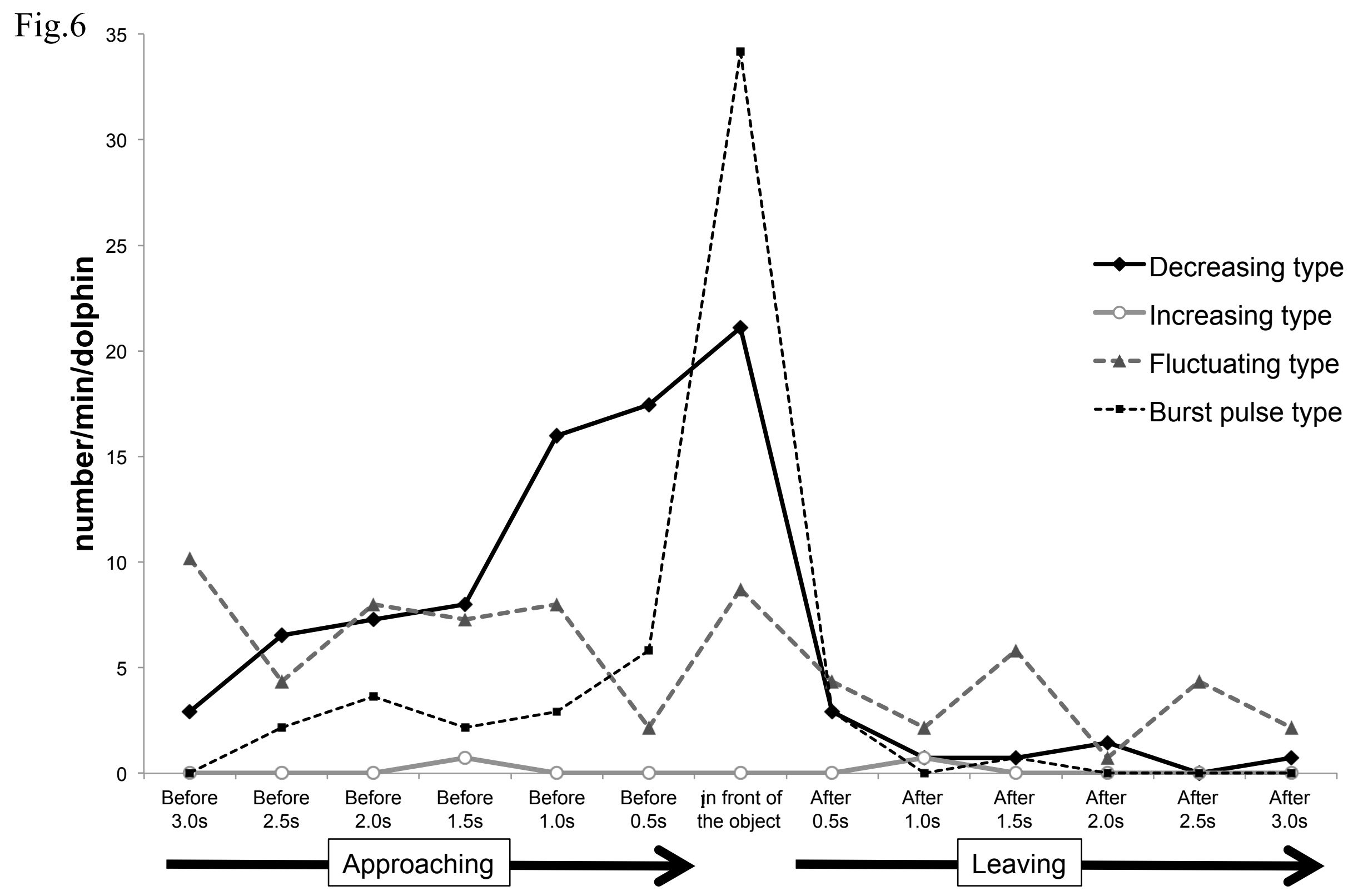


Fig. 7

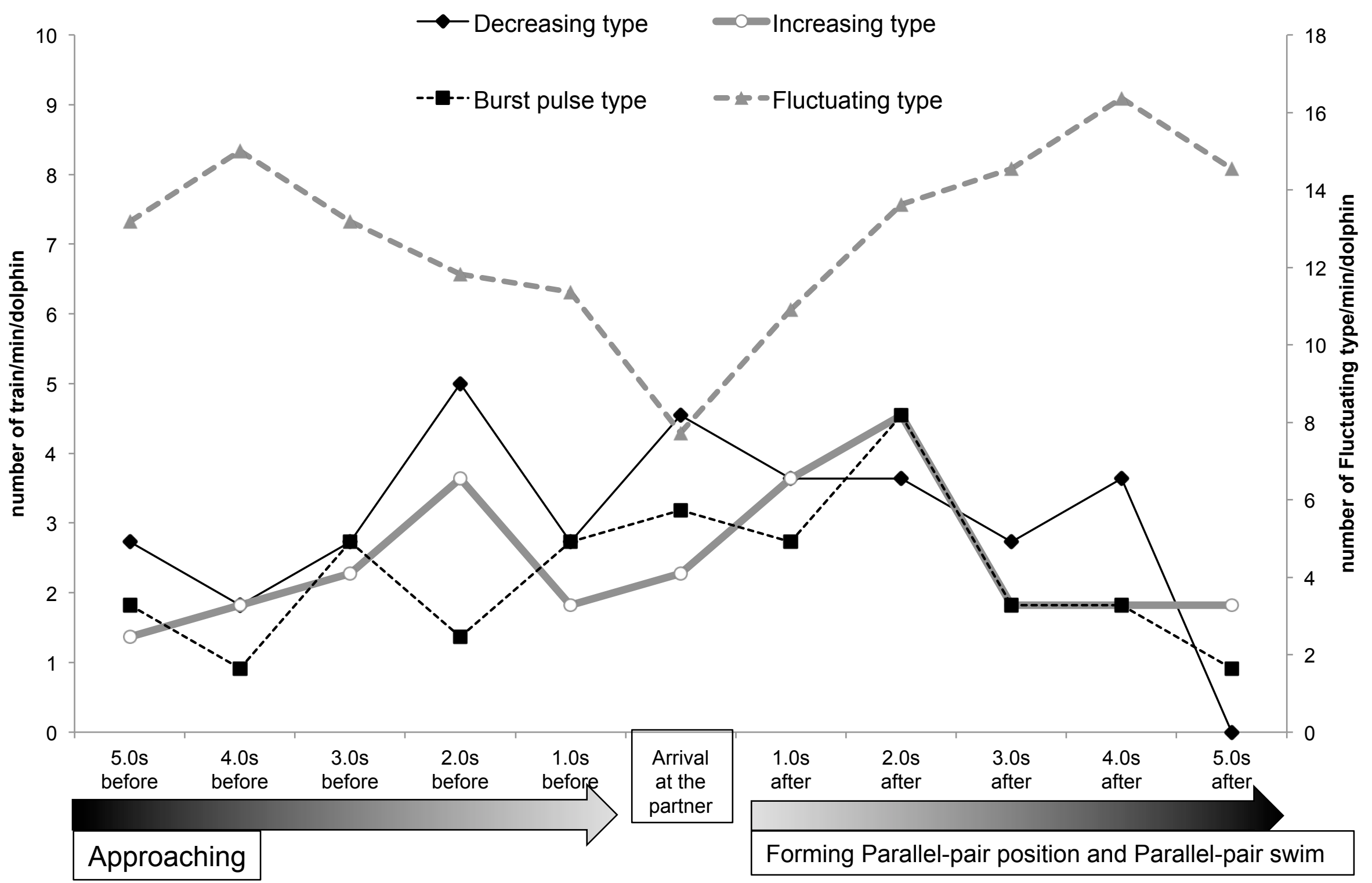




\section{Fig.8}

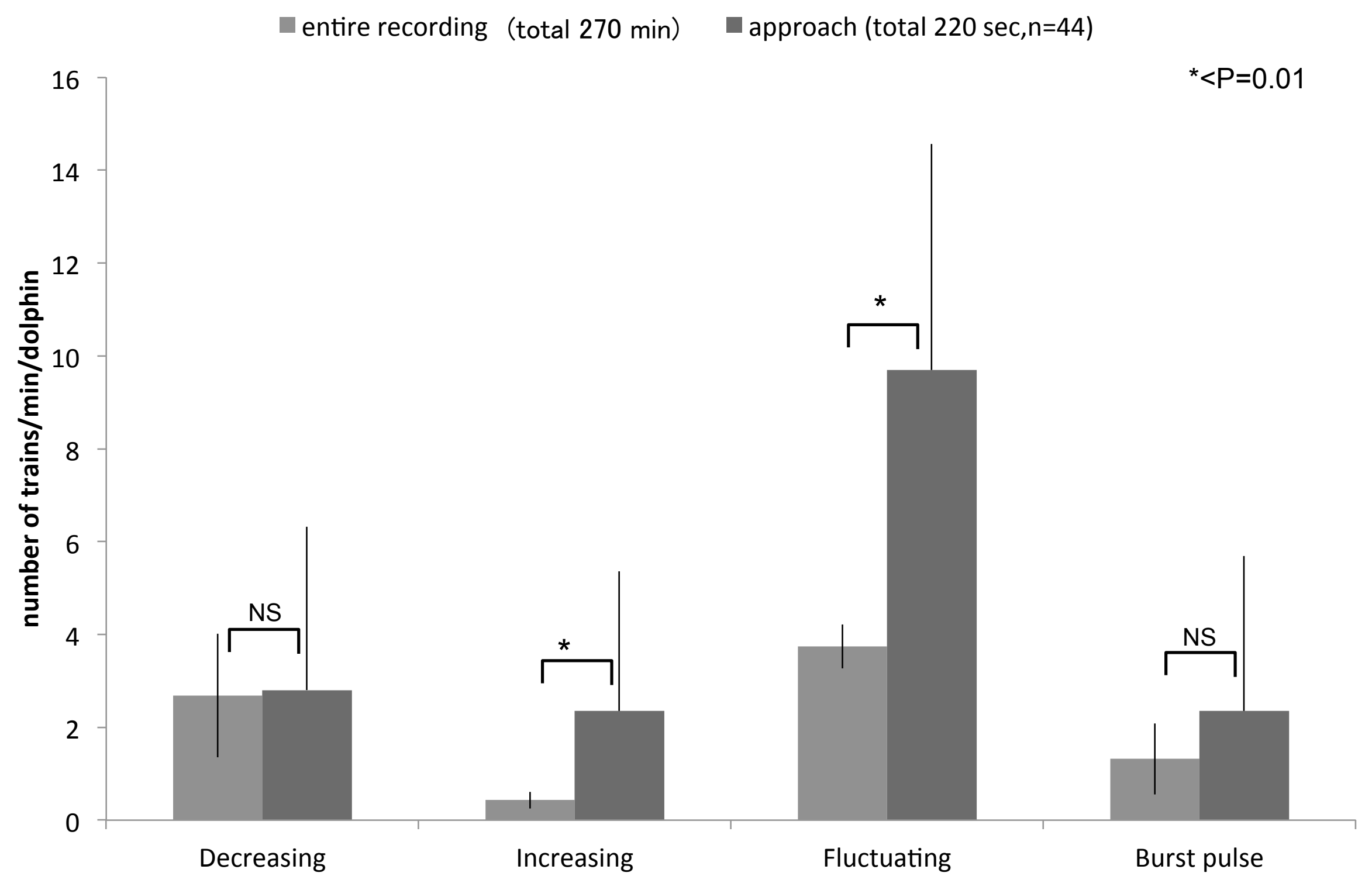


Fig.9

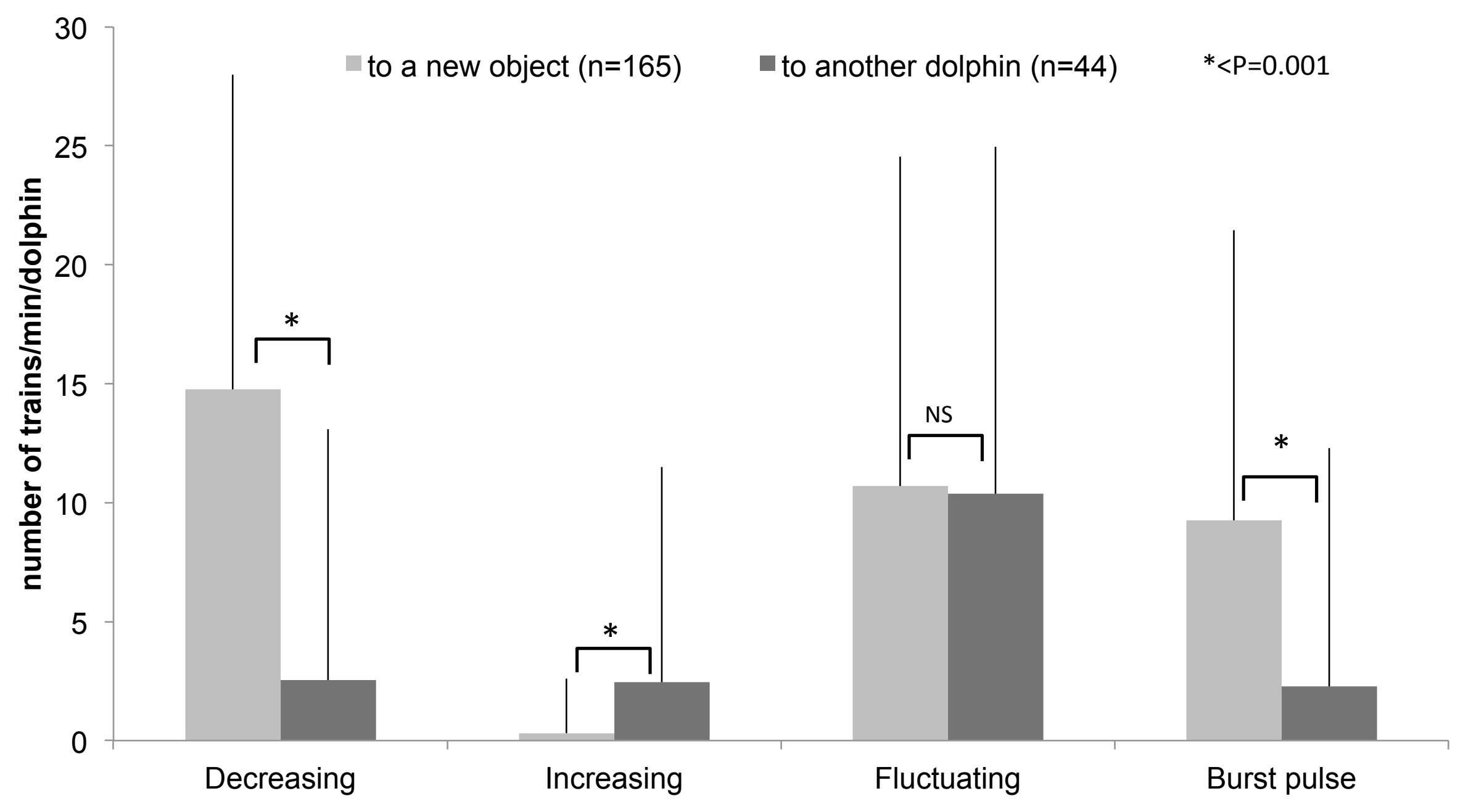


Fig.10

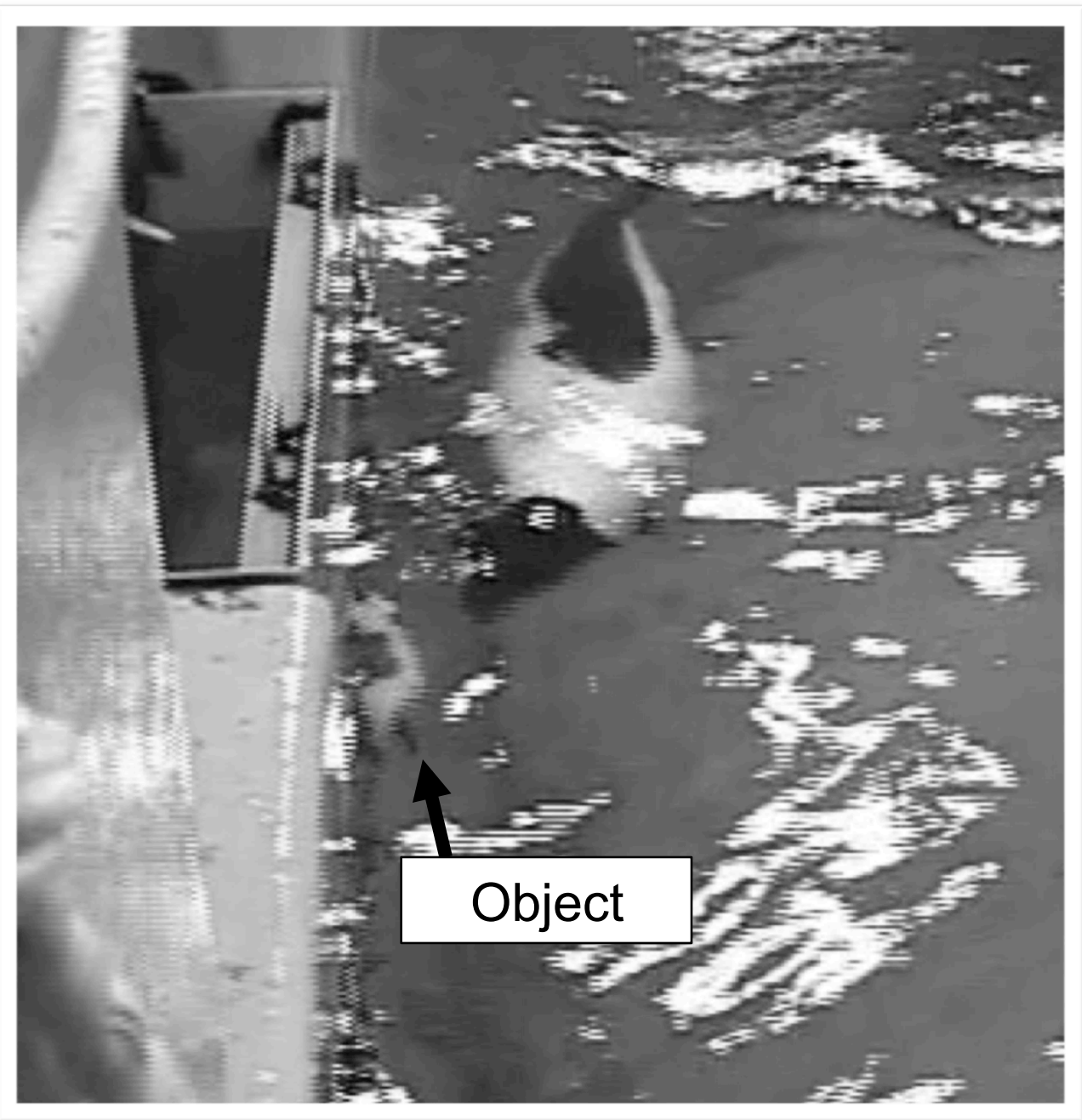


Table. 1

\begin{tabular}{|c|c|c|c|c|c|c|}
\hline \multirow{2}{*}{$\begin{array}{l}\text { Click-train } \\
\text { type (n) }\end{array}$} & \multicolumn{2}{|c|}{$\begin{array}{l}\text { Inter-click interval ( ICI ) } \\
(\mathrm{ms})\end{array}$} & \multicolumn{2}{|c|}{ Duration of the train (ms) } & \multicolumn{2}{|c|}{ Change in ICI (ms) } \\
\hline & Mean \pm SD & Range & Mean \pm SD & Range & Mean \pm SD & Range \\
\hline Decreasing (42) & $25.0 \pm 12.4$ & $1.1-89.5$ & $571.3 \pm 324.6$ & $81.2-1557.9$ & $25.0 \pm 14.3$ & $3.2-69.1$ \\
\hline Increasing (48) & $31.6 \pm 13.4$ & $0.5-99.5$ & $541.4 \pm 264.8$ & $167.9-1399.3$ & $36.0 \pm 18.4$ & $11.2-86.5$ \\
\hline Fluctuating (107) & $29.6 \pm 8.2$ & $10.9-99.3$ & $1344.3 \pm 751.5$ & $392.1-3977.5$ & $62.7 \pm 19.2$ & $13.8-96.3$ \\
\hline Burst Pulse (65) & $3.5 \pm 1.8$ & $1.8-10.7$ & $458.9 \pm 304.4$ & $73.1-1141.3$ & $19.1 \pm 23.2$ & $0.1-75.0$ \\
\hline
\end{tabular}

